\title{
Pengaruh Pembelajaran Di Alam Terhadap Motivasi Belajar Siswa Dalam Pembelajaran Penjas di SD Negeri Cijaksi Kabupaten Sukabumi Tahun Ajaran 2019/2020
}

\section{The Effect Of Learning In Nature On Student Learning Motivation In Learnin Physical Education In Elementary School Cijaksi Sukabumi District In Theacademic Year 2019/2020}

\author{
Abdul Azis \\ Universitas Muhammadiyah, Kota Sukabumi, Jawa Barat, Indonesia \\ Azisss040@gmail.com
}

\begin{abstract}
ABSTRAK
Salah satu masalah pendidikan yang dihadapi di sekolah adalah kurangnya motivasi belajar siswa, khususnya dalam pembelajaran Pendidikan Jasmani di sekolah terdapat beberapa aspek yang dapat mempengaruhi turunnya motivasi siswa salah satunya rendahnya kualitas pembelajaran, maupun dari sarana dan prasarana sekolah yang terbatas. Dalam aspek proses kelemahan terletak pada kegiatan pembelajaran yang kurang mengembangkan keterampilan dasar siswa, sedangkan dari sarana dan prasaran, banyak terdapat alat dan perlatan olahraga yang kurang terurus dan sudah tidak bisa diperbaiki akan tetapi dalam hal sarana terdapat beberapa lapangan dengan pengurusan yang kurang. Penelitian ini bertujuan untuk mengembangkan model pembelajaran di alam atau Jelajah Alam Sekitar berbasis kompetensi untuk jenjang sekolah dasar sebagai salah satu alternatif pembelajaran penjas yang efektif. Disamping ingin mengetahui keunggulan dan kelemahan model pembelajaran penjas yang selama ini digunakan guru di sekolah. Pendekatan penelitian yang digunakan ini adalah penelitian dan eksperimen dengan diawali observasi dan survey di sekolah kelas V dan VI mendapatkan permasalahan kurangnya motivasi belajar dalam pembelajaran penjas. Dari hasil penelitian kelompok kontrol yang mengikuti pembelajaran penjas sebagaimana adanya diketahui memiliki tingkat motivasi melalui pengisian angket dengan nilai rata-rata 66\%, selanjutnya untuk kelompok eksperimen diberikan perlakuan berupa pembelajaran di alam dengan materi ajar permainan tradisional (galasin) memiliki tingkat motivasi lebih tinggi dengan nilai ratarata $81.5 \%$. Perbedaan tersebut merupakan efek dari penerapan perlakuan, efek perlakuan memberikan dampak positif kepada tingkat motivasi belajar siswa dalam pembelajaran Pendidikan Jasmani
\end{abstract}

Kata-kata Kunci: Motivasi, Pembelajaran di alam, Hasil belajar siswa

\section{ABSTRACT}

Especially in physical education learning in schools, there are several aspects that can affect student motivation, one of which is the low quality of learning and limited school facilities and infrastructure. In the aspect of the process of weakness lies in learning activities that do not develop students basic skills, while from facilities and infrastructure, there are many sports equipment and cannot be repaired but in the case of facilities there are several fields with poor management. This study aims to develop a learning model in nature or which is based on competency for elementary school levels as an alternative to effective physical education learning. Besides wanting to know the strengths and weaknesses of the Physical Education learning model 
that has been used by teachers in school. The research approach used is research and experimentation which begins with observations and surveys in the fifth and fifth grade schools, which has the problem of lack of learning motivation in Physical Education learning. From the results of the control group research that followed Physical Education learning as it is known to have a level of motivation through questionnaires with an average value of 66\%, furthermore, the experimental group was given treatment in the form of learning in nature with traditional game teaching materials (galasin) having a higher level of motivation with an average value of $81 \%$, the difference is the effect of the application treatment effect gives a positive impact on the level of student motivation in Physical Education learning.

Keywords: Motivation, Learning in Nature, Student Learning Outcomes

\section{PENDAHULUAN}

Pendidikan jasmani merupakan salah satu mata pelajaran disekolah yang memiliki peran besar terhadap perkembangan perilaku peserta didik seperti kognitif, afektif, dan khususnya aspek psikomotorik. Pendidikan jasmani merupakan mata pelajaran yang wajib diikuti oleh semua peserta didik, karena dalam pembelajran penjas peserta didik dapat bersosialisasi dengan lingkungan dan alam sekitarnya. UNESCO dalam Yuli Purwanto (2011: 13) yang tertera dalam Interntional Charter of Physical Education (1974) mengemukakan: Pendidikan jasmani adalah suatu proses pendidikan seseorang sebagai individu maupun sebagai anggota masyarakat yang dilakukan secara sadar dan sistematik melalui berbagai kegiatan jasmani dalam rangka memperoleh peningkatan kemampuan dan ketersmpilsn jasmani, pertumbuhan kecerdasan dan pembentukan watak.

Pendidikan jasmani (penjas) merupakan pendidikan yang dapat mendukung pencapaian tujuan pendidikan secara keseluruhan. Penjas memiliki potensi untuk mengembangkan domain-domain yang meliputi: kognitif, afektif, dan psikomotor. Pendidikan jasmani adalah fase dari program pendidikan keseluruhan yang memberikan kontribusi, terutama melalui pengalaman gerak, untuk pertumbuhan dan perkembangan secara utuh untuk tiap peseta didik. Pendidikan jasmani didefinisikan sebagai pendidikan melalui gerak dan harus dilaksanakan dengan cara-cara yang tepat agar memiliki makna bagi siswa. Pendidikan jasmani merupakan program pembelajaran yang memberikan perhatian yang proporsional dan memadai pada aspek pembelajaran, yaitu afektif, kognitif, dan psikomotor. Daeur dan Pangrazi dalam Ega Trisna Rahayu (2013: 3). Menurut Nichole dalam Aunurrahman (2014:33) "Belajar merupakan kegaiatan penting setiap orang, termasuk didalamnya belajar dan bagaimana seharusnya belajar. Dalam survey memeperlihatkan bahwa $82 \%$ anak-anak yang masuk sekolah pada usia 5 atau 6 tahun memiliki citra diri yang positif tentang kemampuan belajar mereka sendiri. Tetapi angka tinggi tersebut menurun drastis menjadi hanya 18\% waktu mereka berusia 16 tahun. 
Konsekuaensinya, 4 dari 5 remaja dan orang dewasa melalui pengalaman belajarnya yang baru dengan persasaan ketidaknyamanan.

Menurut Hamanik dalam Kompri (2015:231) "motivasi sangat menentukan tingkat berhasil atau gagalnya perbuatan belajar siswa. Belajar tanpa adanya motivasi kiranya akan sangat sulit untuk berhasil. Sebab, seseorang yang tidak mempunyai motivasi dalam belajar, tidak akan mungkin melakukan aktivitas belajar". Nasution dalam Rangga (2016:10) mengemukakan "anak yang mempunyai intelegensi tinggi mungkun gagal karena kurang motivasi. Hasil baik tercapai dengan motivasi yang tepat. Anak gagal tak begitu saja dipersilahkan, mungkin gurulah yang tidak berhasil memberi motivasi yang membangkitkan pada anak". Menurut Slameto dalam Rangga (2016:19) "mengingat pentingnya motivasi bagi peserta didik dalam belajar, maka guru diharapkan dapat membangkitkan motivasi belajar peserta didiknya dalam usaha ini banyak cara yang dapat dilakukan untuk menciptakan kondisi-kondisi tertentu yang dapat membangkitkan motivasi belajar". Menurut Sage Weinberg dan Gould dalam Komarudin (2013:23) "motivation can defined simply as the direction and intensity of one's effort". Menurut Hamanik dalam Kompri (2015:231) "motivasi sangat menentukan tingkat berhasil atau gagalnya perbuatan belajar siswa. Belajar tanpa adanya motivasi kiranya akan sangat sulit untuk berhasil. Sebab, seseorang yang tidak mempunyai motivasi dalam belajar, tidak akan mungkin melakukan aktivitas belajar".

Berdasarkan observasi dan pengamatan yang dilakukan peneliti pada tanggal pada tanggal 1 s/d 8 desember 2019 di SD negeri Cijaksi meliputi cara pembelajaran guru penjas, sarana prasarana, materi ajar yang diajarkan pada siswa, model pembelajaran yang digunakan guru, dan keaktifan peserta didik saat mengikuti pelajaran penjas. Adapun hasil dari observasi adalah sebagai berikut:

Observasi di SD Negeri Cijaksi Kabupaten Sukabumi diperoleh gambaran jumlah populasi sebanyak 53 siswa dari kelas I sampai kelas VI, dari sarana-prasarana sekolah memiliki sarana cukup banyak dari bidang olahraga, karena tempat bangunan sekolah terdapat di komplek perkebunan karet PTPN VIII Nusantara Cikaso, antara lain gedung bulu tangkis, lapangan bola, lapangan voli, lapangan tenis meja, akan tetapi dari segi pengurusan kurang baik, sehingga banyak lapangan yang sudah lama tidak dipakai menjadi kotor dan penuh dengan debu sehingga para siswa tidak berminat bermain di lapangan tersebut, dari prasarana di Sekolah banyak alat-alat yang tidak terpelihara dengan baik, sebagai contoh banyak bola sepak dan bola voli yang disimpan digudang dengan banyak debu dan raket bulu tangkis yang tidak bersenar. Dalam pembelajaran penjas siswa di kelas V dan VI rata- 
rata memliki motivasi yang rendah, hal tersebut diketahui dari sikap dan prilaku dalam mengikuti pembelajaran, ada sebagian siswa dalam pembelajaran penjas tidak memakai pakaian olahraga lengkap, pulang di lebih awal pada akhir pembelajaran, dan tidak mengikuti gerak yang diperagakan oleh guru. Dalam permasalahan tersebut peneliti ingin meningkatkan motivasi belajar siswa dalam pembelajaran penjas dengan pembelajaran untuk mengenal alam sekitarnya dan mempelajari betapa pentingnya menjaga lingkungan sekitar.

Dalam penelitian di alam atau jelajah alam sekitar (JAS), Menurut Ridlo dan Rudiyatmi dalam Husamah (2013:36) “pendekatan jelajah alam merupakan pendekatan pembelajaran yang memanfaatkan lingkungan alam sekitar kehidupan peserta didik baik lingkungan fisik, sosial, teknologi, maupun budaya sebagai objek belajar biologi yang fenomenanya dipelajari melalui kerja ilmiah”. Pembelajaran JAS menekankan pada kegiatan pemebelajaran di situasi dunia nyata, sehingga selain dapat membuka wawasan berfikir yang beragam dari seluruh peserta didik, pendidikan ini memungkinkan peserta didik dapat mempelajari berbagai konsep dan cara mengaitkannya dengan dunia nyata sehingga hasil belajarnya lebih berdaya guna. Peneliti menggunakan materi ajar permainan tradisional (galasin) Menuru Mahendra (2009: 4.9) Permainan Galasin atau Galah Asin banyak dimainkan oleh nak-anak daerah Sunda. Permainan ini memerlukan kecepatan lari dan kelincahan bergerak serta mengelak agar mudah bebas dari kejaaran lawan. Proses bermainnya cukup mudah, yaitu masing-masing regu membuat skor dengan cara menyentuh atau masuk ke daerah lawan tanpa dicegah oleh lawan. Lapangan yang diperlukan untuk jalannya permainan ini adalah ruang terbuka ukuran sedang, yang memungkinkan terjadinya saling kejar antara kedua regu yang berhadapan.

\section{METODE PENELITIAN}

Metode dalam penelitian ini adalah metode kuantitatif. Menurut Sugiyono (2018:8) metode penelitian kuantitatif adalah metode penelitian yang berlandaskan pada filsafat positivism, digunakan untuk penelitian pada populasi atau sampel tertentu, teknik pengambilan sampel pada umumnya dilakukan secara random, pengumpulan data menggunakan instrument penelitian analisis data bersifat kuantitatif dengan tujuan untuk menguji hipotesis yang telah ditetapkan. Penelitian ini juga menggunakan penelitian eksperimen. Menurut Sugiono (2018:6) "metode penelitian eksperimen merupakan metode penelitian yang digunakan untuk mencari treatmen (perlakuan) tertentu”. Desain penelitian ini menggunakan desaind intact group comparison suatu eksperimen mengandung upaya 
perbandigan mengenai akibat suatu tritmen tertentu dengan suatu tritmen lainnya yang berbeda, atau dengan yang tanpa tritmen. Didalam referensi mengenai eksperimen konvensional yang sederhana, biasanya dibuatkan suatu kelompok eksperimen dan suatu kelompok kontrol.

Instrumen penelitian ini menggunakan angket tertutup Menurut Sugiyono (2018:142) "kuesioner merupakan teknik pengumpulan data yang dilakukan dengan cara memberi seperangkat pertanyaan atau pernyataan tertulis kepada responden untuk dijawabnya". Kuesioner ini digunakan untuk memperoleh data tentang kedisiplinan dan motivasi belajar peserta didik. Pada penelitian menggunakan angket tertutup dalam pengumpulan data, angket tertutup adalah angket yang mengehendaki jawaban pendek, atau jawabannya diberikan dengan menumbuhkan tanda tertentu. Angket disusun dengan disertai alternatif jawaban. Winarno dalam Rangga (2016:24). Dalam penelitian ini jumlah sampel terdiri dari 20 siswa untuk mengetahui tingkat niali motivasi siswa dengan menggunakan angket pernyataan tertutup dengan jumlah 10 soal dengan masing-masing pilihan sebagai berikut: (SS) Sangat Sesuai, (S) sesuai, (TS) Tidak Sesuai, (STS) Sangat Tidak Sesuai. Sampel dibagi menjadi dua kelompok, yaitu kelompok kontrol dan kelompok eksperimen dengan sampel dari kelas V dan VI dibagi dengan 1:1. Kelompok eksperimen diberikan perlakuan berupa pembelajaran di alam dengan materi ajar permainan tradisional (galasin), dan kelompok kontrol tidak diberi perlakuan.

\section{HASIL PEMBAHASAN}

Hasil penelitian sebagai berikut:

a) Validitas

Validasi adalah ukuran yang menunjukan tingkat-tingkat kevalidan atau kesahihan suatu instrumen. Suharismi Arikunto dalam Rangga (2016:28). Untuk memperoleh perangkat instrumen tersebut di ujicobakan terlebih dahulu dengan responden untuk uji coba. Sedangkan dalam penelitian ini menggunakan software IBM SPSS statistics 26, tujuannya agar dapat dikejakan dengan lebih mudah dan akurat. angket dinyatakan valid jika rxy $>r_{\text {tabel}}$, dengan $r_{\text {tabel }}=0.444$. Validitas dilakukan di SD Negeri Warudoyong Kota Sukabumi dengan jumlah sampel 20 kelas VI pada tanggal 8 Januari 2020. Nilai rata-rata dari angket yang di validitas 0.737 maka nilai $0.737>0.444$ jadi angket dari penelitian ini dinyatakan valid. 


\begin{tabular}{|c|c|c|c|}
\hline No Item & $\mathrm{r}_{\mathrm{xy}}$ & $\mathrm{r}_{\text {tabel }} 15 \%(20)$ & Keterangan \\
\hline 1 & 0,786 & 0,444 & Valid \\
\hline 2 & 0,730 & 0,444 & Valid \\
\hline 3 & 0,629 & 0,444 & Valid \\
\hline 4 & 0,740 & 0,444 & Valid \\
\hline 5 & 0,729 & 0,444 & Valid \\
\hline 6 & 0,730 & 0,444 & Valid \\
\hline 7 & 0,618 & 0,444 & Valid \\
\hline 8 & 0,811 & 0,444 & Valid \\
\hline 9 & 0,811 & 0,444 & Valid \\
\hline 10 & 0,786 & 0,444 & Valid \\
\hline
\end{tabular}

b) Reabilitas

Reabilitas menuujukan pada suatu pengertian bahwa suatu instrumen dapat cukup dapat dipercaya untuk digunakan suatu alat pengumpulan data karena instrument tersebut sudah cukup baik“. Suharismi Arikunto, dalam Rangga 2016:28). Penggunaan teknik uji rehabilitasada penelian ini menggunakan menggunakan software IBM SPSS statistics 26 alasannya adalah data yang diambil melalui angket agar lebih mudah dan akurat. Kuisioner adalah data mengenai penerapan nilai-nilai positif pada motivasi peserta didik, dimana indicator yang terdapat pada kuisioner yang akan disajikan sebagai instrument dalam penelitian yidak dapat dipisahkan dengan yang lain. Harga $r_{11}$ yang diperoleh dari perhitungan dikonsultasikan dengan harga $r$ pada table produk momen dengan $a=5 \%$. Instrument dikatakan reliabel apabila harga $r>$ harga rtable. Dalam penelitian ini Uji reliabilitas menggunakan software IBM SPSS statistics 26. Dalam penelitian diketahui bahwa nilai harga $r=0.908$ dan nilai $r_{\text {tabel }}=0.444$. Jika nilai $0.908>0444$ maka angket dalam penelitian ini dinyatakan reabel.

Tabel Uji Reabilitas

\begin{tabular}{|c|c|c|c|}
\hline variabel & $\mathrm{r}_{\mathrm{xy}}$ & $\mathrm{r}_{\text {tabel}} 5 \%(20)$ & Keterangan \\
\hline $\mathrm{X} 1$ & 0,908 & 0,444 & Reilabel \\
\hline
\end{tabular}

c) Hasil Penelitian Nilai Norma 
Tabel Rentang Norma Motivasi Kelompok Kontrol

\begin{tabular}{|c|c|c|c|}
\hline NO & Kelompok & Rentang Norma & Kategori \\
\hline 1 & & $81-100$ & Sangat Tinggi \\
\hline 2 & X2 (66.25) & $61-80$ & Tinggi \\
\hline 3 & & $41-60$ & Sedang \\
\hline 4 & & $21-40$ & Rendah \\
\hline 5 & & $0-20$ & Sangat Rendah \\
\hline
\end{tabular}

Tabel Rentang Norma Motivasi Kelompok Eksperimen

\begin{tabular}{|c|c|c|c|}
\hline NO & Kelompok & Rentang Norma & Kategori \\
\hline 1 & X1 (81.5\%) & $81-100$ & Sangat Tinggi \\
\hline 2 & & $61-80$ & Tinggi \\
\hline 3 & & $41-60$ & Sedang \\
\hline 4 & & $21-40$ & Rendah \\
\hline 5 & & $0-20$ & Sangat Rendah \\
\hline
\end{tabular}

Dari angket pernyataan Dalam penelitian telah diketahui nilai norma motivasi siswa, dari kelompok kontrol nilai norma siswa sebesar $66 \%$ dengan dikategorikan tinggi. Dan norma dari nilai motivasi siswa pada kelompok eksperimen memiliki peningkatan yang signifikan yaitu dengan nilai sebesar $81 \%$ dengan kategori sangat tinggi.

Diagram Batang Tingkat Motivasi Total

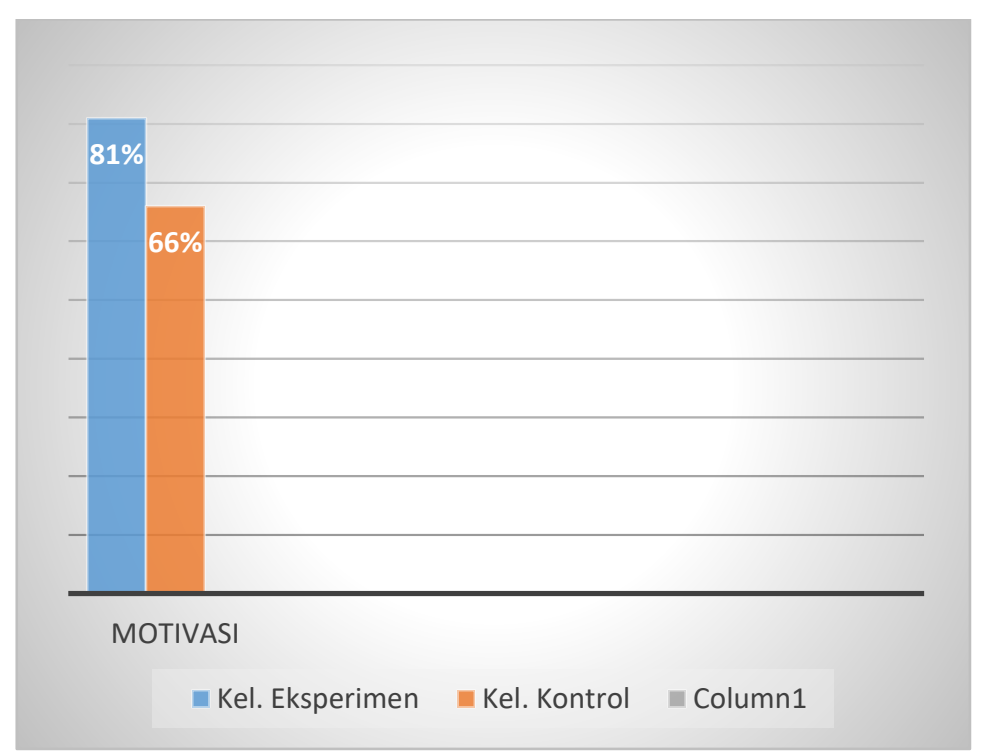


d) Pada hasil penelitian siswa kelompok kontrol diberikan angket pernyataan dengan beberapa indikator yaitu adanya dorongan dalam pembelajaran penjas memiliki tingkat motivasi dengan rata-rata $67 \%$ dan adanya penghargaan dalam pembelajaran penjas dengan jumlah 66\%. Dalam kelompok eksperimen peningkatan motivasi terlihat signifikan diantaranya dalam adanya dorongan dalam pembelajaran penjas memiliki tingkat motivasi dengan rata-rata $83 \%$ dan indikator adanya penghargaan dalam pembelajaran penjas berjumlah rata-rata $80 \%$. Jadi dalam hasil penelitian berupa perlakuan dan angket diketahui bahwa tingkat motivasi kelas eksperimen lebih tinggi dari kelas kontrol. Hasil angket dan perlakuan dari penelitian motivasi belajar siswa dalam pembelajaran penjas dalam perlakuan berupa permainan tradisional telah diperoleh, dimana data ketercapaian pada setiap indikator yaitu sebagai berikut.

Gambar Diagram Tingkat Indikator Motivasi

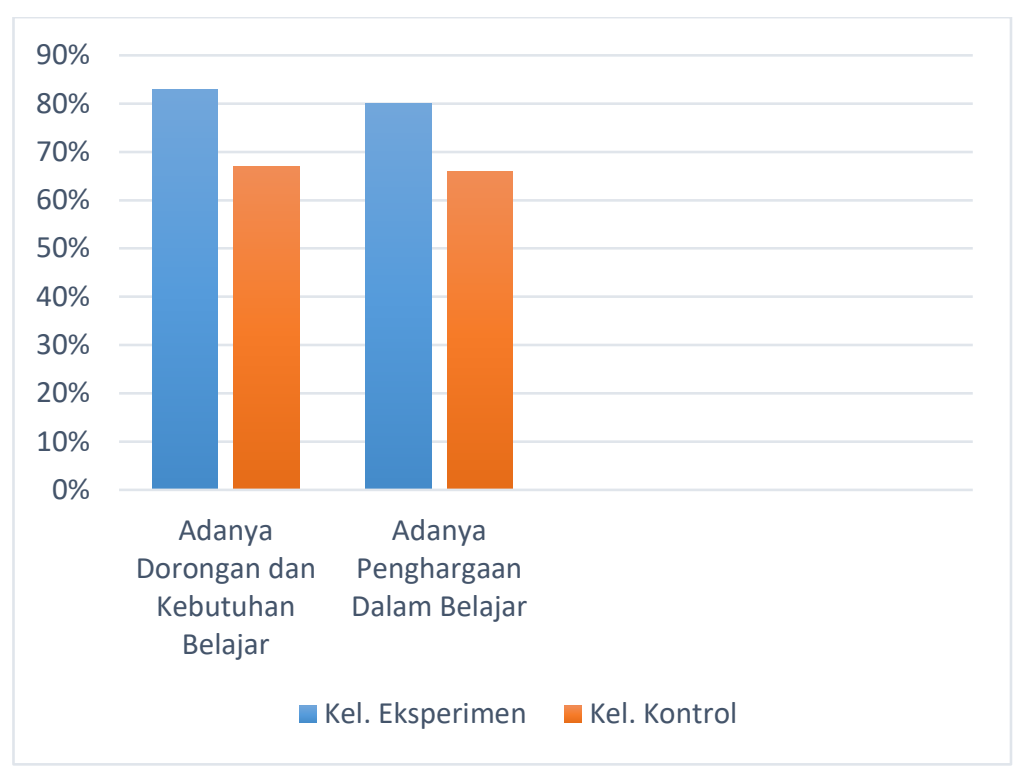

Gambar 3.2 Diagram Peningkatan Indikator Motivasi siswa

\section{KESIMPULAN}

Dalam penelitian tingkat indikator motivasi diketahui bahwa nilai rata-rata motivasi siswa kelas kontrol sebesar $66 \%$ dan untuk tingkat motivasi kelas 
ekperimen $81 \%$, jadi tingkat motivasi siswa kelas eksperimen lebih signifikan dari kelas kontrol..

Maka dapat disimpulkan bahwa pembelajaran dengan menggunakan metode pembelajaran di alam dengan materi ajar permainan tradisional dapat meningkatkan motivasi belajar siswa dalam pembelajaran Pendidikan Jasmani (PENJAS) pada kelas V dan VI SD Negeri Cijaksi Kabupaten Sukabumi tahun ajaran 2019/2020.

\section{DAFTAR PUSTAKA}

Aunurrahman. (2014). Belajar dan Pembelajaran. Bandung: Alfabeta

Haniyah, S. (2018). Implementasi Model Contextual Teaching and Learning Untuk Meningkatkan Motivasi Belajar Matematika Siswa Di Kelas Tinggi. Disertai Sarjana pada FKIP UMMI Kota Sukabumi: Tidak Diterbitkan.

Husamah. (2013). Outdor Learning. Jakarta: Prestasi Pusaka.

Komarudin. (2013). Psikologi Olahraga. Bandung: Rosda.

Kompri. (2015). Motivasi Pembelajaran. Bandung: Rosdakarya.

Mahendra, A. (2009). Permainan Anak dan Aktivitas Ritmik. Jakarta: Universitas Terbuka

Purwanto, Y. (2011). "Model Pembelajaran Pendidikan Jasmani Modifikasi Permainan Bola Tangan Melalui Pendekatan Lingkungan Luar Sekolah Pada Siswa Kelas V SD Negeri 02 Banaran Kecamatan Grabag Kabupaten Magelang”. Universitas Negeri Semarang. Pendidikan Jasmani Kesehatan dan Rekreasi Fakultas Ilmu Keolahragaan 2011.

Rangga, A. (2016). Motivasi Siswa Kelas VII Di SMP IT Khalifah Boarding School Dalam Pembeajaran Penjasorkes. Disertasi Sarjana pada FKIP UMMI Sukabumi: Tidak Diterbitkan

Rosdiani, D. (2015). Kurikulum Pendidikan Jasmani. Bandung: Alfabeta Sugiyono, (2018). Metode Penelitian. Bandung: Alfa Beta

Trisna, E. (2013). Strategi Pembelajaran Pendidikan Jasmani. Bandung: Alfabeta. Uno, B. (2013). Teori Motivasi \& Pengukurannya. Bandung: Bumi Aksara 